\title{
Mucinous Cystic Neoplasm of the Cystic Duct: A Rare Location of a Rare Entity
}

\author{
Nicholas J. Caldwell ${ }^{1}$, Ilham Farhat ${ }^{2}$, Sarag Boukhar ${ }^{2}$ \\ 1. Pathology, Carver College of Medicine, University of Iowa, Iowa City, USA 2. Pathology, University of Iowa Hospitals \\ and Clinics, Iowa City, USA
}

Corresponding author: Nicholas J. Caldwell, nicholas-caldwell@uiowa.edu

\begin{abstract}
Mucinous cystic neoplasms (MCNs) are uncommon cystic lesions that arise in the liver and biliary system (MCN-LBS) and the pancreas (MCN-P) and rarely arise from the extrahepatic biliary system. Histologically, these lesions are defined by the presence of variably mucin-producing epithelium with ovarian-like, hypercellular mesenchymal stroma. Herein, we present a case of extrahepatic MCN-LBS in a 51-year-old woman. This lesion arose from the cystic duct and was removed via laparoscopic cholecystectomy. Histologic examination confirmed the diagnosis. To our knowledge, this is the third case report of an MCN-LBS arising from the cystic duct in the English literature. In this article, we review clinical and histologic characteristics of MCNs and present two other reports of MCN-LBS of the cystic duct.
\end{abstract}

Categories: Pathology, Gastroenterology

Keywords: mucinous cystic neoplasm, cystic duct, biliary cystadenoma

\section{Introduction}

Mucinous cystic neoplasms (MCNs) of the liver and biliary system (MCN-LBS) are rare, benign cystic lesions with a reported incidence of 1 case per 20,000 to 100,000 person-years [1]. Per World Health Organization (WHO) diagnostic criteria, MCNs occur exclusively in females. Patients typically present in the fifth to sixth decades of life with symptoms related to the anatomic location and space-occupying nature of the lesion $[2$, 3]. Macroscopically, these are multilocular cystic lesions without communication to the biliary duct system. Microscopically, the cystic spaces are typically lined by cuboidal to columnar, variably mucin-producing epithelium (unless surface-denuded) overlying a hypercellular bland spindle cell proliferation resembling ovarian stroma, known as ovarian-like or ovarian-type stroma. MCN-LBS occur predominantly within the liver and intrahepatic biliary system, and there is a variably reported, yet low, percentage of these lesions occurring in the extrahepatic biliary system $[4,5]$. Herein, we present a case of extrahepatic MCNLBS arising from the cystic duct.

Review began 03/25/2021 Review ended 04/05/2021 Published 04/09/2021

\section{๑) Copyright 2021}

Caldwell et al. This is an open access article distributed under the terms of the Creative Commons Attribution License CC-BY 4.0., which permits unrestricted use, distribution, and reproduction in any medium, provided the original author and source are credited.

\section{Case Presentation}

The patient is a 51-year-old woman who is a former smoker with a past medical history of hypertension and gastrointestinal reflux disease. She initially presented with a few months of right upper quadrant abdominal pain with subsequent ultrasonography reporting a $1 \mathrm{~cm}$ non-mobile stone within the fundal region of the gallbladder (Figure 1). 


\section{Cureus}

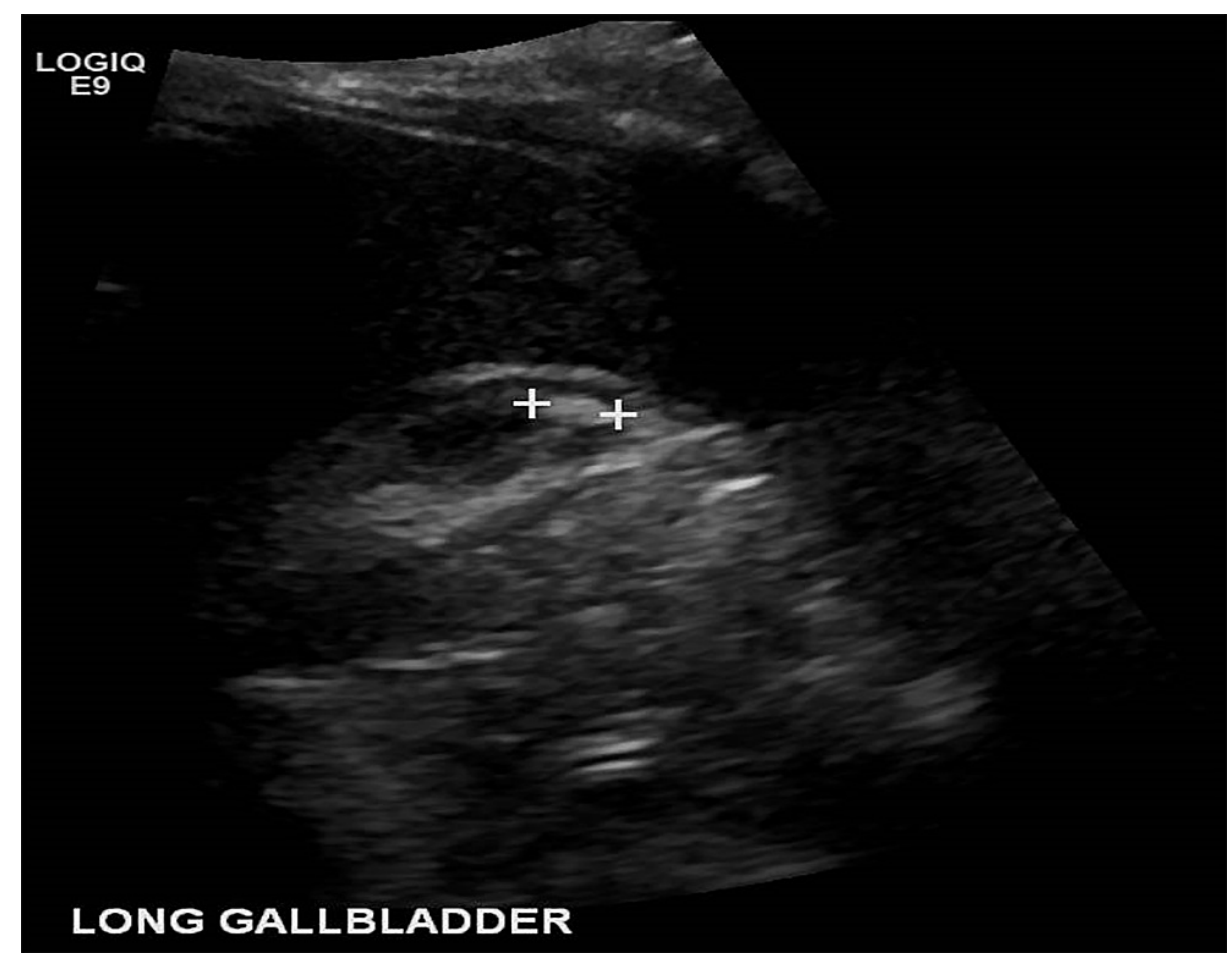

\section{FIGURE 1: Abdominal ultrasound}

Preoperative ultrasonography highlighting the assumed non-mobile gallstone (between the plus signs) within the gallbladder fundus.

She eventually received a laparoscopic cholecystectomy revealing a grossly unremarkable gallbladder without gallstones. Microscopic evaluation revealed a small cystic lesion within a cystic duct section involving the surgical margin. The cyst wall showed a bland, cuboidal to columnar, mucinous epithelial lining overlying an ovarian-like, mesenchymal stroma (Figures 2, 3). 


\section{Cureus}

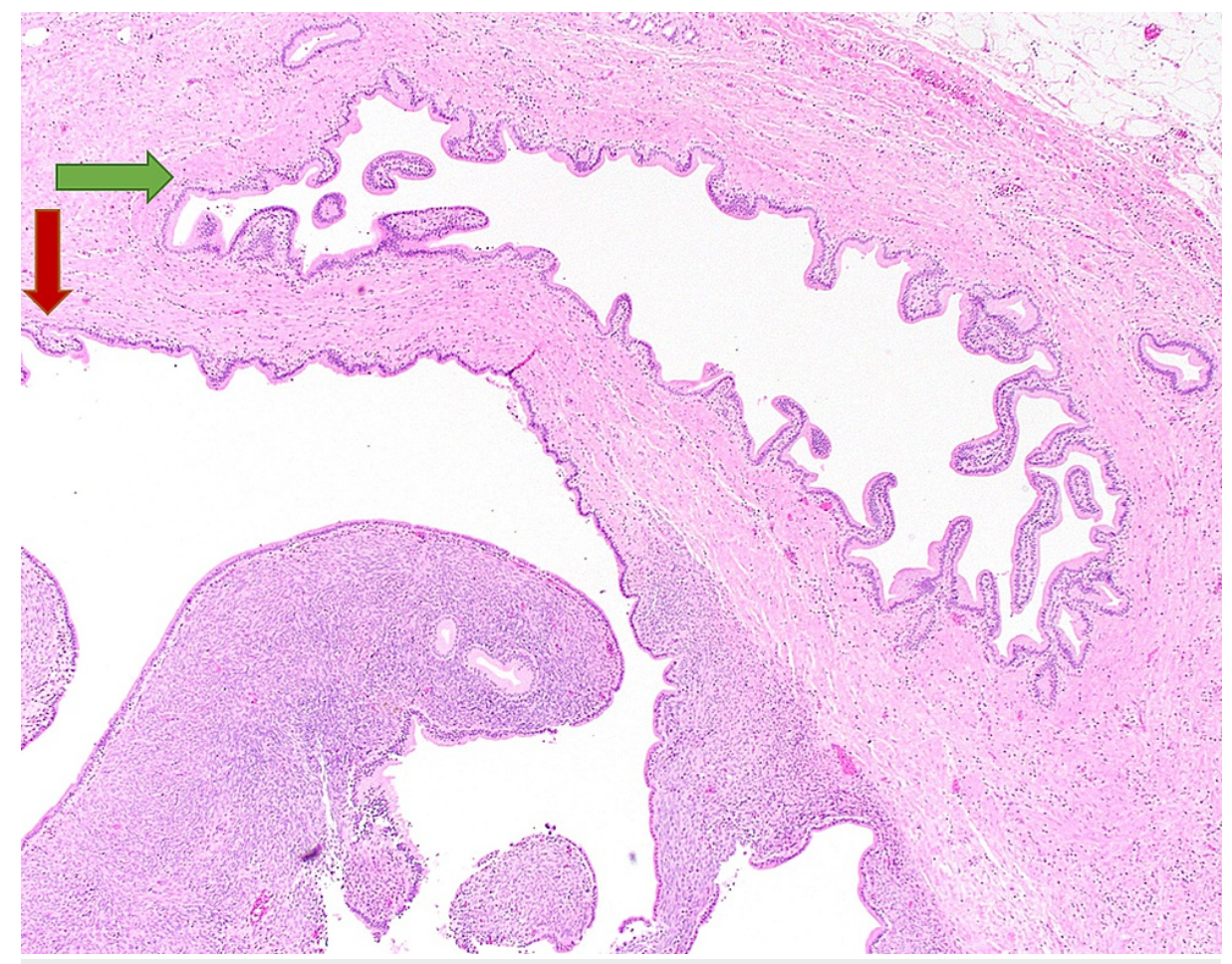

FIGURE 2: Mucinous cystic neoplasm arising from the cystic duct

A low-power view demonstrating a cystic lesion on the lower left (red arrow), lined by bland mucinous epithelium with underlying hypercellular stroma, and cystic duct lumen on the upper right (green arrow). Note the absence of luminal communication between the cystic duct and the adjacent cystic lesion (H\&E, $\mathrm{x} 4$ magnification).

$\mathrm{H} \& \mathrm{E}=$ hematoxylin and eosin 


\section{Cureus}

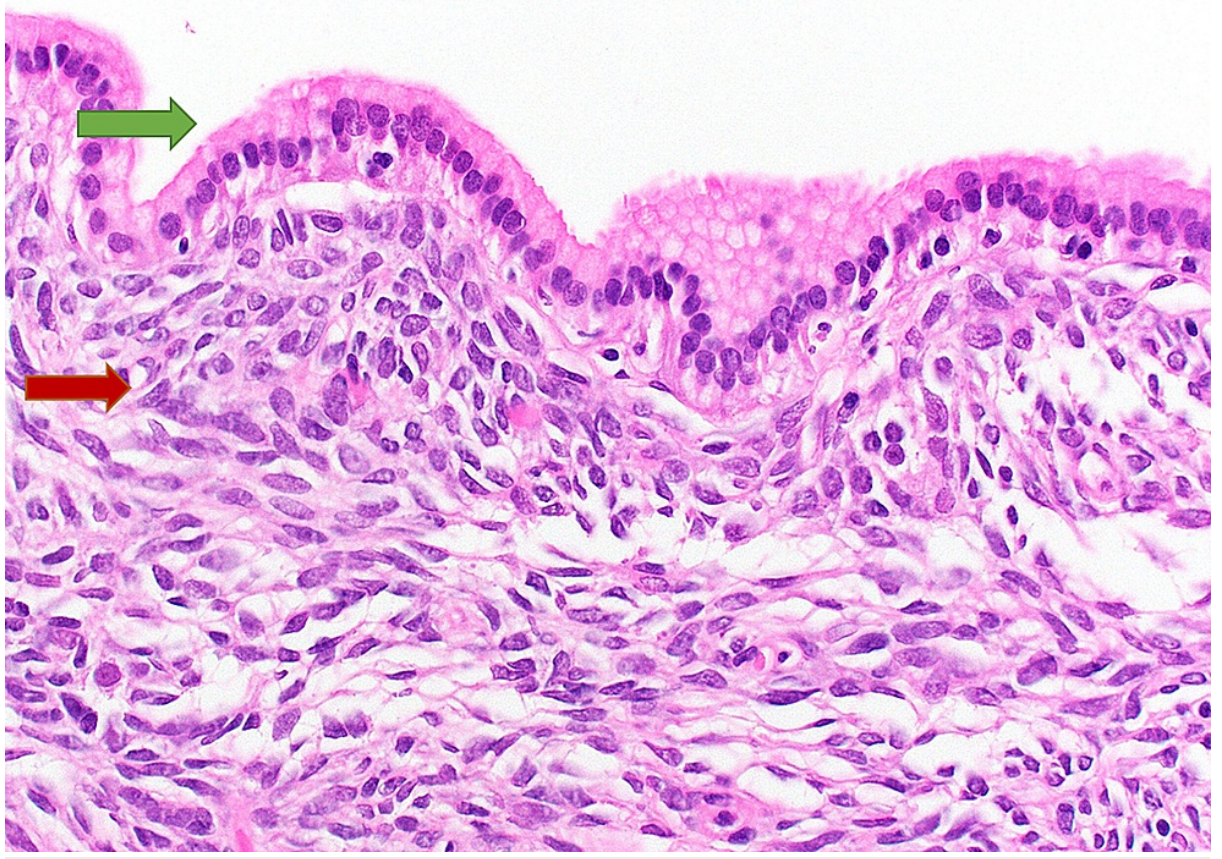

FIGURE 3: Mucinous cystic neoplasm arising from the cystic duct

A high-power view demonstrating the single layer of mucinous cuboidal to columnar epithelium (green arrow) and the pathognomic ovarian-like, mesenchymal stroma (red arrow) formed of densely cellular bland spindle cells (H\&E, $x 40$ magnification).

H\&E = hematoxylin and eosin

The immunoreactivity of the ovarian-like stroma to estrogen receptor further confirmed the morphologic impression of mucinous cystic neoplasm (Figure 4). 


\section{Cureus}

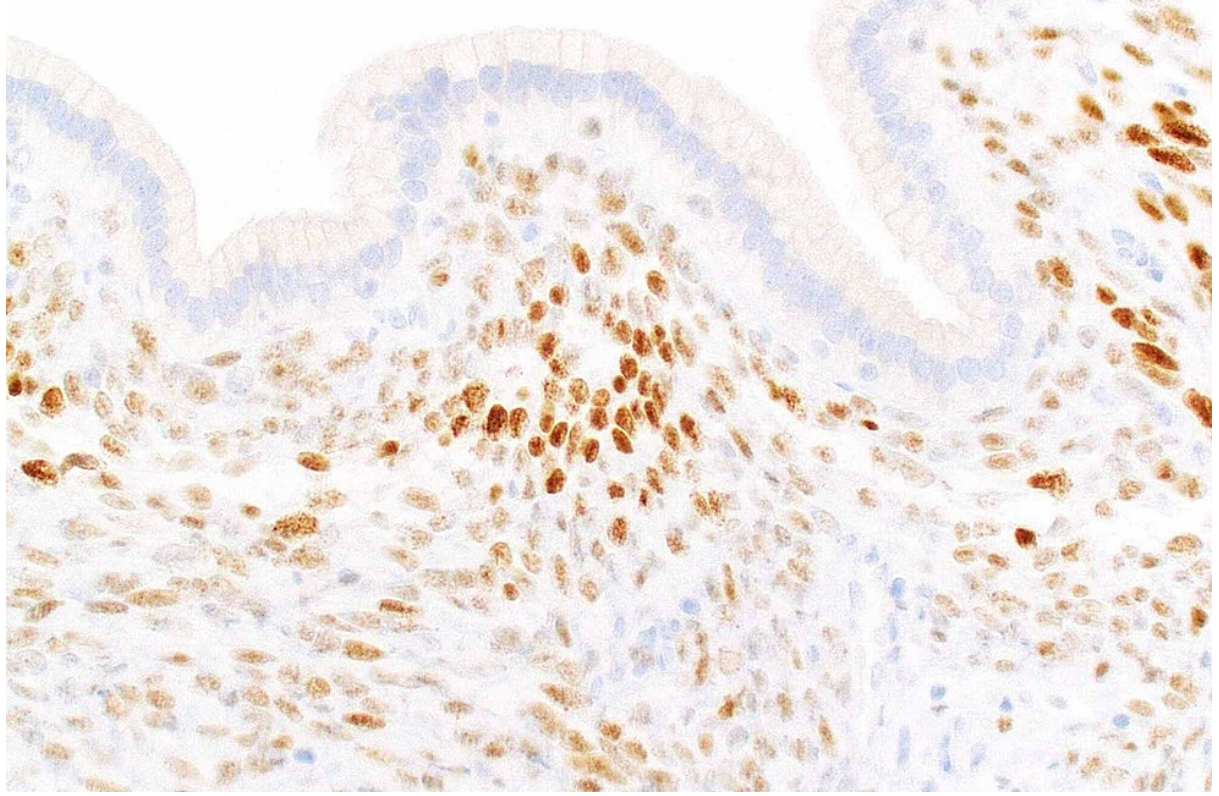

FIGURE 4: Mucinous cystic neoplasm arising from the cystic duct (IHC)

A high-power view of the lesion from the same area depicted in Figure 2 shows nuclear positivity (brown color staining) of the stromal cells (ovarian-like stroma) to ER immunostaining (DAB, x40 magnification).

IHC = immunohistochemistry, ER = estrogen receptor, DAB = 3-3'-diaminobenzidine

The entire specimen was subsequently submitted for examination and sections of the background gallbladder revealed chronic active cholecystitis with no evidence of tumor involvement (Figure 5). No highgrade dysplasia or associated carcinoma was identified. She is currently under medical observation with periodic imaging. Surveillance magnetic resonance imaging (MRI) obtained 4 and 16 months postoperatively were negative for disease recurrence, and as of her last follow-up (16 months postoperatively), she was asymptomatic. 


\section{Cureus}

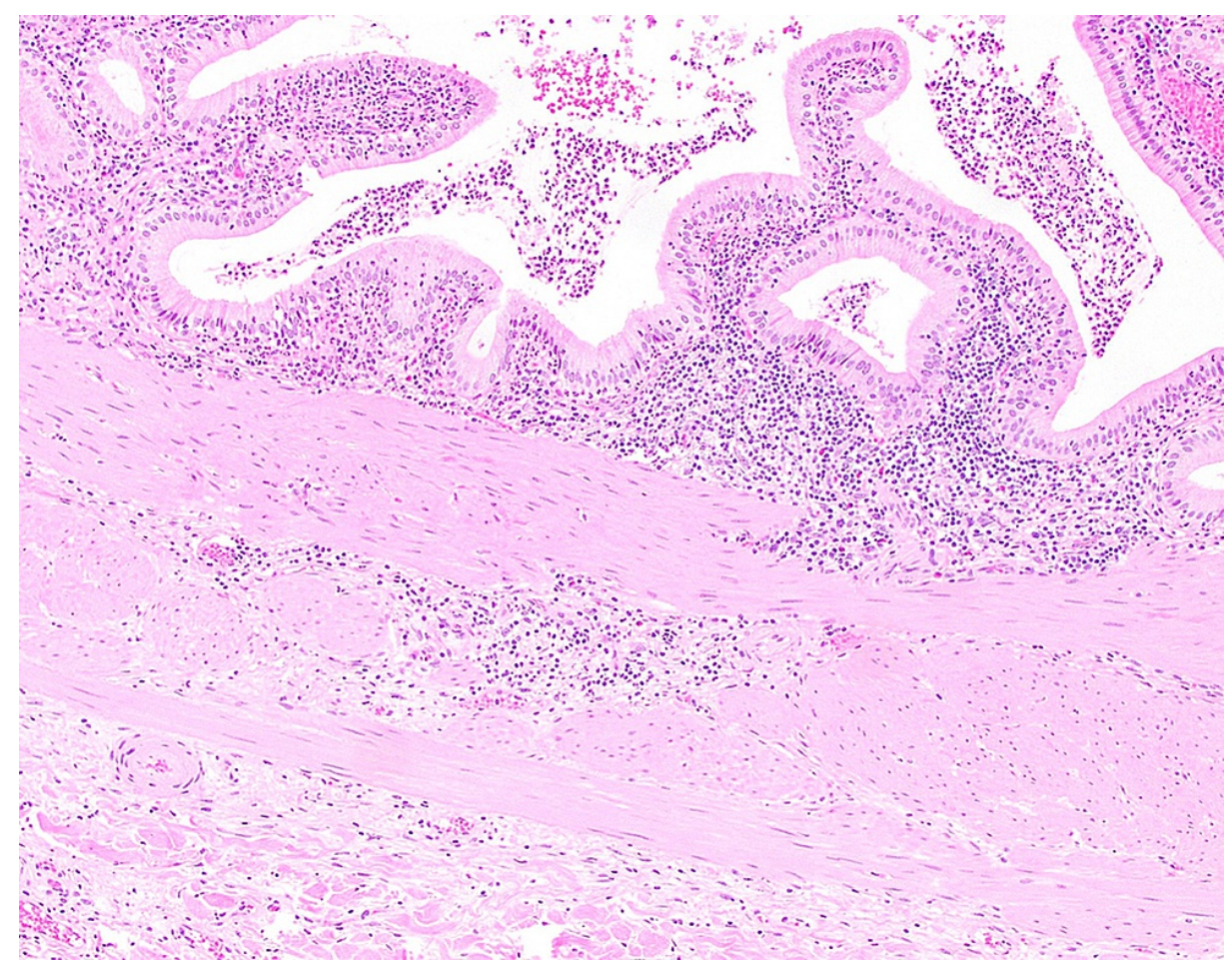

\section{FIGURE 5: Chronic active cholecystitis}

A medium-power view of the gallbladder demonstrating mixed mucosal inflammation extending to the underlying, mildly thickened, muscular layer (H\&E, x10 magnification).

$\mathrm{H} \& \mathrm{E}=$ hematoxylin and eosin

\section{Discussion}

MCNs most commonly arise in the liver and pancreas and rarely arise from the extrahepatic biliary system $[2$ 6]. As evident grossly and radiographically, these lesions are multiloculated with variable presence of loculations, septae, calcifications, papillary projections, and small mural nodules [7, 8]. The reported average lesion size is approximately $11 \mathrm{~cm}$ (range $1.4-30 \mathrm{~cm}$ ) [2, 3]. MCNs rarely have associated focal highgrade dysplasia and/or invasive carcinomas that are unable to be detected preoperatively $[2,3,6,9]$. Studies reporting cases of MCN-LBS with associated dysplasia are presented in Table 1. Extensive sampling of these lesions is recommended and it is the authors' practice to submit the entire lesion for microscopic examination whenever possible. Because of the risk of dysplasia and carcinoma, management typically involves complete surgical excision with an excellent prognosis with complete lesion removal [10].

\begin{tabular}{|c|c|}
\hline Author (year) & Findings of Dysplasia in MCN-LBS \\
\hline Quigley (2018) [2] & $2(6 \%)$ of $36 \mathrm{MCN}-\mathrm{LBS}$ with high-grade dysplasia with microscopic foci of invasion \\
\hline Zhelnin (2017) [3] & $3(9 \%)$ of 32 MCN-LBS with invasive carcinoma, $1(3 \%)$ of 32 MCN-LBS with focal high-grade dysplasia \\
\hline Fujikura (2017) [9] & $1(13 \%)$ of $8 \mathrm{MCN}-$ LBS with high-grade dysplasia \\
\hline Zen (2011) [6] & $2(7 \%)$ of 29 MCN-LBS with borderline malignancy, 1 (3\%) of 29 MCN-LBS with carcinoma in situ \\
\hline
\end{tabular}

TABLE 1: Reported incidences of dysplasia and carcinoma in mucinous cystic neoplasm of liver and biliary system

MCN-LBS = mucinous cystic neoplasms of the liver and biliary system

Essential histologic criteria for MCN-LBS - initially introduced in 2010 and recently restated in 2019 - is listed in the World Health Organization (WHO) Classification of Tumours [1, 11]. Chief among these is the requirement for demonstrable ovarian-like, mesenchymal stroma with at least focal positively for 
immunohistochemical stains estrogen receptor (ER) and progesterone receptor (PR). Like the presence of an associated carcinoma, this stroma may be focal, thus requiring adequate sampling of the lesion to confirm or refute its presence [2]. Additional criteria include non-communication of the lesion with the bile duct system and neoplastic epithelium with at least partial mucin staining. Interestingly, the WHO also lists female exclusivity of the lesion as an essential diagnostic feature of the entity. Arguments against this diagnostic criteria take aim at the need for mucinous epithelium and lack of bile duct communication; authors have proposed that lesions without these characteristics but with the presence of ovarian-like, mesenchymal stroma could potentially be considered as MCNs [12, 13, 14]. Additionally, there is literature describing MCNs in men [3].

Reviewing scientific literature regarding this entity is challenging due to inconsistent lesion nomenclature and incomplete mention of the current essential histologic diagnostic criteria for MCNs. Prior to 2010, the entity of MCN-LBS did not exist; rather, cystic lesions of the liver and extrahepatic biliary system were commonly referred to as "biliary cystadenomas." Lesions referred to as biliary cystadenomas were typically cystic lesions with varying epithelium with or without the presence of the ovarian-like stroma that is so crucial for the diagnosis of MCN today. As such, the findings of larger sample studies of biliary cystadenoma cannot easily be applied to MCN-LBS $[5,15,16]$.

Reports of biliary cystadenomas and MCNs do not universally describe the histopathologic criteria needed to make a current diagnosis of MCN. This is best demonstrated with a comparison of two literature reviews regarding MCNs of the gallbladder; while both manuscripts were published in 2018, one (Sugawara et al.) reports three cases of gallbladder MCNs [17] while the other (Rivero-Soto et al.) reports sixteen [4]. However, many of the cases cited by Rivero-Soto's manuscript either report a lack of ovarian-like stroma or are missing evidence needed for current MCN diagnosis. Our review of the literature revealed at least four gallbladder MCNs - the three described in Sugawara et al.'s manuscript and the one reported in Rivero-Soto et al.'s manuscript.

As alluded to previously, there is scant literature describing MCNs arising in the extrahepatic biliary system that fulfill the essential histopathologist diagnostic criteria. Among these reports, there are only two case reports of MCNs arising from the cystic duct $[17,18]$. Clinical and pathologic data from these two reports alongside our presented case are displayed in Table 2. All cases occurred in women and had histologically proven ovarian-like stroma. Mucinous epithelium was noted in two of the cases. Two of the lesions' sizes were on the lower end of the reported range for MCN size; compared to an average MCN-P (pancreas) size of $6.6 \mathrm{~cm}$ and MCN-L (liver) size of $11.2 \mathrm{~cm}$, these lesions were $1.8 \mathrm{~cm}$ and $1.0 \mathrm{~cm}$ in their greatest dimension [3]. These small lesions likely became symptomatic due to their proximity to the cystic duct. The report of an $8.5 \mathrm{~cm}$ MCN of the cystic duct had an accompanying gallbladder component, which likely explains its increased size and the patient's lack of symptoms. None of the three cases had any associated high-grade dysplasia or invasiveness, and all were treated via surgical removal without any noted recurrence at followup. 


\section{Cureus}

\begin{tabular}{|c|c|c|c|}
\hline Author, Year & Marcotte, 2013 [18] & Sugawara, 2018 [17] & Current Case, 2021 \\
\hline Patient Demographics & 50-year-old woman & 70-year-old woman & 51-year-old woman \\
\hline Presenting symptoms & $\begin{array}{l}\text { Nausea, vomiting, postprandial RUQ } \\
\text { abdominal pain }\end{array}$ & Asymptomatic & RUQ abdominal pain \\
\hline Anatomic location & Cystic Duct & Gallbladder and Cystic Duct & Cystic Duct \\
\hline Size & $1.8 \times 1.5 \times 1.4 \mathrm{~cm}$ & $8.5 \times 6.0 \mathrm{~cm}$ & $1.0 \mathrm{~cm}$ \\
\hline Gross Appearance & Multiloculated, cystic & Multiloculated, cystic & Normal \\
\hline Epithelium & Not described & $\begin{array}{l}\text { Cuboidal to columnar mucin- } \\
\text { producing cell }\end{array}$ & Columnar mucinous cell \\
\hline Epithelial Dysplasia? & Not described & Low-grade dysplasia present & Absent \\
\hline Stroma & OLS & OLS & OLS \\
\hline IHC of OLS & Not described & ER negative, PR positive & ER positive \\
\hline $\begin{array}{l}\text { Communication with biliary } \\
\text { structures }\end{array}$ & Absent & Absent & Absent \\
\hline Management & Laparoscopic Cholecystectomy & Cholecystectomy & $\begin{array}{l}\text { Laparoscopic } \\
\text { Cholecystectomy }\end{array}$ \\
\hline Long-term Outcome & Not described & $\begin{array}{l}\text { No recurrence eight years } \\
\text { postoperatively }\end{array}$ & $\begin{array}{l}\text { No recurrence } 14 \text { months } \\
\text { postoperatively }\end{array}$ \\
\hline
\end{tabular}

\section{TABLE 2: Reported Cases of Mucinous Cystic Neoplasm arising from the Cystic Duct}

$\mathrm{RUQ}=$ right upper quadrant, IHC = immunohistochemistry, OLS = ovarian-like stroma, ER = estrogen receptor, $\mathrm{PR}=$ progesterone receptor

\section{Conclusions}

MCNs are a distinct clinical entity distinguished from other cystic lesions by their ovarian-like, hypercellular mesenchymal stroma, among other criteria. While most of these lesions arise from the liver and biliary system (MCN-LBS) and pancreas (MCN-P), these lesions occasionally arise in the extrahepatic biliary system. We reported the third case of MCN-LBS arising from the cystic duct and discussed the clinical and histopathologic characteristics of the lesion. MCN-LBS arising from the cystic duct are histologically identical to those of the liver; however, it may present at a smaller size due to their proximity with critical biliary structures. Continued acknowledgement of WHO diagnostic criteria and nomenclature for this entity is important to further define clinical characteristics of this lesion. For this reason, the authors support the WHO's recommendation for discontinuation of the historic term "biliary cystadenoma."

\section{Additional Information \\ Disclosures}

Human subjects: Consent was obtained or waived by all participants in this study. Conflicts of interest: In compliance with the ICMJE uniform disclosure form, all authors declare the following: Payment/services info: All authors have declared that no financial support was received from any organization for the submitted work. Financial relationships: All authors have declared that they have no financial relationships at present or within the previous three years with any organizations that might have an interest in the submitted work. Other relationships: All authors have declared that there are no other relationships or activities that could appear to have influenced the submitted work.

\section{References}

1. WHO Classification of Tumours Editorial Board: Digestive System Tumours: WHO Classification of Tumours, 5th Edition, Volume 1. WHO Classification of Tumours Editorial Board (ed): International Agency for Research on Cancer, Lyon; 2019.

2. Quigley B, Reid MD, Pehlivanoglu B, et al.: Hepatobiliary mucinous cystic neoplasms with ovarian type stroma (so-called "hepatobiliary cystadenoma/cystadenocarcinoma"): clinicopathologic analysis of 36 cases illustrates rarity of carcinomatous change. Am J Surg Pathol. 2018, 42:95-102. 10.1097/pas.0000000000000963

3. Zhelnin K, Xue Y, Quigley B, et al.: Nonmucinous biliary epithelium is a frequent finding and is often the 
predominant epithelial type in mucinous cystic neoplasms of the pancreas and liver. Am J Surg Pathol. 2017, 41:116-20. 10.1097/pas.0000000000000745

4. Rivero-Soto RJ, Hossein-Zadeh Z, Coleman J, Ahuja V: A mucinous cystic neoplasm originating from the gallbladder: a case report and literature review. Perm J. 2019, 23: 10.7812/TPP/18-077

5. Davies W, Chow M, Nagorney D: Extrahepatic biliary cystadenomas and cystadenocarcinoma: report of seven cases and review of the literature. Ann Surg. 1995, 222:619-25. 10.1097/00000658-199511000-00003

6. Zen Y, Pedica F, Patcha VR, et al.: Mucinous cystic neoplasms of the liver: a clinicopathological study and comparison with intraductal papillary neoplasms of the bile duct. Mod Pathol. 2011, 24:1079-89. 10.1038/modpathol.2011.71

7. Boyum JH, Sheedy SP, Graham RP, et al.: Hepatic mucinous cystic neoplasm versus simple biliary cyst: assessment of distinguishing imaging features using CT and MRI. AJR Am J Roentgenol. 2021, 216:403-11. 10.2214/ajr.20.22768

8. Jeong D, Jiang K, Anaya DA: Mucinous cystic neoplasm of the liver masquerading as an echinococcal cyst: radiologic-pathologic differential of complex cystic liver lesions. J Clin Imaging Sci. 2016, 6:12. 10.4103/2156-7514.179426

9. Fujikura K, Akita M, Abe-Suzuki S, Itoh T, Zen Y: Mucinous cystic neoplasms of the liver and pancreas: relationship between KRAS driver mutations and disease progression. Histopathology. 2017, 71:591-600. 10.1111/his.13271

10. Arnaoutakis DJ, Kim Y, Pulitano C, et al.: Management of biliary cystic tumors: a multi-institutional analysis of a rare liver tumor. Ann Surg. 2015, 261:361-7. 10.1097/SLA.0000000000000543

11. Bosman FT, Carneiro F, Hruban RH, Theise ND: WHO Classification of Tumours of the Digestive System: WHO Classification of Tumours, 4th Edition, Volume 3. Bosman FT, Carneiro F, Hruban RH, Theise ND (ed): International Agency for Research on Cancer, Lyon; 2010.

12. Kunovsky L, Kala Z, Svaton R, Moravcik P, Mazanec J, Husty J, Prochazka V: Mucinous cystic neoplasm of the liver or intraductal papillary mucinous neoplasm of the bile duct?: a case report and a review of literature. Ann Hepatol. 2018, 17:519-24. 10.5604/01.3001.0011.7397

13. Shibata H, Ohike N, Norose T, et al.: Mucinous cystic neoplasms lined by abundant mucinous epithelium frequently involve kras mutations and malignant progression. Anticancer Res. 2017, 37:7063-8. 10.21873/anticanres. 12178

14. Anand S, Chandrasekar S, Raja K, Pottakkat B: Mucinous cystic neoplasm of the liver with biliary communication: an exception to the current classification. BMJ Case Rep. 2019, 12:10.1136/bcr-2018227063

15. Devaney K, Goodman ZD, Ishak KG: Hepatobiliary cystadenoma and cystadenocarcinoma: a light microscopic and immunohistochemical study of 70 patients. Am J Surg Pathol. 1994, 18:1078-91.

16. Soares KC, Arnaoutakis DJ, Kamel I, Anders R, Adams RB, Bauer TW, Pawlik TM: Cystic neoplasms of the liver: biliary cystadenoma and cystadenocarcinoma. J Am Coll Surg. 2014, 218:119-28. 10.1016/j.jamcollsurg.2013.08.014

17. Sugawara S, Hirai I, Watanabe T, Tezuka K, Kimura W: A case of mucinous cystic neoplasm of the gallbladder. Clin J Gastroenterol. 2018, 11:428-32. 10.1007/s12328-018-0850-8

18. Marcotte E, Afaneh C, Pomp A, Cherqui D: Image of the month-quiz case . JAMA Surg. 2013, 148:395-6. 10.1001/jamasurg.2013.317a 